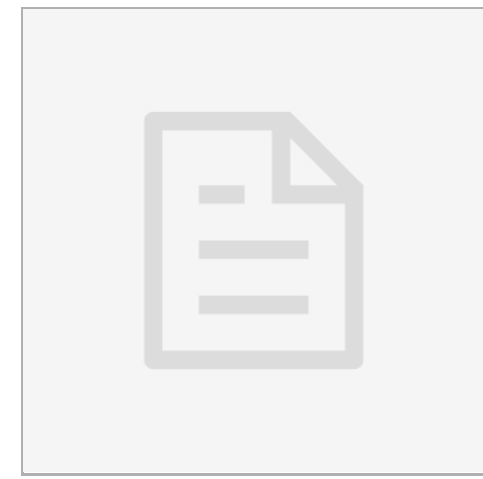

FEB 07, 2019

\section{open ठaccess}

\section{DOI:}

dx.doi.org/10.17504/protocol s.io.xvffn $3 n$

\section{Protocol Citation: Priota} Islam 2019. Tracking acute response of $\mathrm{C}$ elegans to cocaine. protocols.io https://dx.doi.org/10.17504/p rotocols.io.xvffn3n

License: This is an open access protocol distributed under the terms of the Creative Commons Attribution License, which permits unrestricted use, distribution, and reproduction in any medium, provided the original author and source are credited

Protocol status: Working We use this protocol and it's working

Created: Feb 07, 2019

Last Modified: Feb 07, 2019

PROTOCOL integer ID: 20103

\section{(3) Tracking acute response of $C$ elegans to cocaine}

\section{Priota Islam ${ }^{1}$}

${ }^{1}$ Imperial College London

\section{Behavioural Genomics}

\section{Priota Islam}

Imperial College London

\section{ABSTRACT}

Our aim is to study addiction in $\mathrm{C}$ elegans with cocaine being the drug choice of abuse. This short experiment is done to check how the worms react instantaneously upon exposure to this drug for the first time.

\title{
Preparing worms
}

1 - Chunk WT N2 on 3 maintenance plates 
- Bleach the plates after 2 days following the protocol for Bleach synchronization of celegans

- Refeed the starved L1s on 4 different plates that are OP50 seeded, $72 \mathrm{hr}$ prior to the experiment day

\section{Preparing Imaging plates}

2 - Prepare and pour Low peptone NGM on 35mm imaging plates following the protocol for Making low peptone NGM and Plate pouring

- Store the plates at $4 \mathrm{C}$ till in use

- Take 6 plates for control and 6 for cocaine (Or more plates as required)

- Prepare cocaine solution to have a final concentration of 50uM when $35 \mathrm{ul}$ is added to a plate with $3.5 \mathrm{ml}$ agar (Use DI water)- So $5 \mathrm{mM}$ need to be prepared as it will get diluted 100X when added to the imaging plate

- Dissolve $2.5 \mathrm{mg}$ of cocaine hydrochloride in $1471 \mathrm{ul} \mathrm{DI}$ water $=5 \mathrm{mM}$ cocaine hydrochloride

- Pipette $35 \mathrm{ul}$ of the cocaine solution to the plates and let dry (1-2hrs) under a hood

- Similarly, pipette the $35 \mathrm{ul}$ of water on the control plates and let them dry for the same time

\section{Imaging on the multi worm tracker}

\section{Pre-Imaging set-up}

- Clean the rectangular glass plate with ethanol and lint free tissue

- Switch ON the rig

- Align the movable part till desired position and lock it by pressing ON (If you want to move it again press EMO, to lock again twist the EMO knob and press ON again)

- Log in to the 3 PCs (Password: BehavGenom709 (BehavGenom710 for PC 3)

- Change the screen lock time to 20 mins

- Set up destination folder (PC -> Data Part 1 -> Run script (init_exp.ps1) -> Name the folder with the date as (year month date e.g. 20181011)

- Turn on the software GECKO on each pc and check the following:

i) Recording mode: 15 mins

ii) Video format: hdf5

iii) Output folder: Select the folder created earlier

iv) Press the drop-down arrow beside the RECORD icon to make sure ALL CAMERA option is selected if you want both the cameras in use otherwise select CURRENT CAMERA option

\section{Actual Imaging}

- With a hair pick, pick 5 adult worms onto each imaging plates, place the plates on the rectangular glass plate underneath the cameras

- Place the worm plates agar side up with the lids off

- Check the focus on each camera of each PC

- Record immediately

\section{Post Imaging}

- Turn OFF the rig and close GECKO

- Run the script to copy the data to the network (PC -> Data Part 1 -> Run script 
(move_files_anyPC.ps1)

- Change back the lock screen time to 1 minute

- Discard the plates

- See the protocol for video analysis to proceed with the analysis 